ARTIFICIAL SATELLITES, Vol. 46, No. 3 - 2011
DOI: 10.2478/v10018-012-0003-0

\title{
ACCURACY AND AVAILABILITY OF EGNOS - RESULTS OF OBSERVATIONS
}

\author{
Andrzej Felski, Aleksander Nowak \\ Polish Naval Academy, \\ a.felski@amw.gdynia.pl \\ Tomasz Woźniak \\ Polish Air Navigation Services Agency
}

\begin{abstract}
According to SBAS concept the user should receive timely the correct information about the system integrity and corrections to the pseudoranges measurements, which leads to better accuracy of coordinates. In theory the whole system is permanently monitored by RIMS stations, so it is impossible to deliver the faulty information to the user. The quality of the system is guaranteed inside the border of the system coverage however in the east part of Poland lower accuracy and availability of the system is still observed. This was the impulse to start an observation and analysis of real accuracy and availability of EGNOS service in the context of support air-operations in local airports and as the supplementation in hydrographic operations on the Polish Exclusive Zone.
\end{abstract}

A registration has been conducted on three PANSA stations situated on airports in Warsaw, Krakow and Rzeszow and on PNA station in Gdynia. Measurements on PANSA stations have been completed permanently during each whole month up to end of September 2011. These stations are established on Septentrio PolaRx2e receivers and have been engaged into EGNOS Data Collection Network performed by EUROCONTROL. The advantage of these registrations is the uniformity of receivers. Apart from these registrations additional measurements in Gdynia have been provided with different receivers, mainly dedicated sea-navigation: CSI W ireless 1, NOVATEL OEMV, Sperry Navistar, Crescent V-100 and R110 as well as Magellan FX420.

The main object of analyses was the accuracy and availability of EGNOS service in each point and for different receivers. Accuracy has been analyzed separately for each coordinate. Finally the temporarily and spatial correlations of coordinates, its availability and accuracy has been investigated.

The findings prove that present accuracy of EGNOS service is about $1,5 \mathrm{~m}(95 \%)$, but availability of the service is controversial. The accuracy of present EGNOS service meets the parameters of APV I and even APV II requirements, as well as any maritime and hydrography needs. However introducing this service into the practice demands better availability, because the gaps in receiving the proper information from the system appear too often and are too long at the moment. Additionally it was noticed very random character of availability and no correlation of this parameter in the different point of observations. In spite the correct EGNOS work the accuracy of the coordinates is not predictable in the local conditions. So in authors' opinion Local Airport Monitoring should be deployed if EGNOS would have to serve to the local airport service.

Keywords: EGNOS, integrity, accuracy 


\section{INTRODUCTION}

Nowadays the accessibility of navigational systems is important mostly because of satellite systems causes that usually we have at our disposal the excess of the information. In navigation practice any evaluation of PNT systems must be executed with the respect of accuracy, availability and continuity of positioning service. The set of these parameters constitutes the complex information about integrity of the system which is understood as the "measure of the trust that can be placed in the correctness of the information delivered by the system" [FRP, 2008]. It must be noticed, that nowadays mentioned parameters are referred to navigation service, not to the system. It means the proper works of all elements and proper cooperation of them. In other words we can say the navigational service may deliver wrong information even if the receiver causes appearance of the correct work. The essence of this sentence is that integrity of the system should take into account environmental condition and it is possible the incorrect work of such systems composed from correctly working elements.

This is one of starting hypothesis of PECS project no. 98087 "The formal model of valuation of availability of EGNOS measurements with defined level of accuracy" conducted by Polish Naval Academy with cooperation of The Polish Air Navigation Services Agency (PANSA).

In the same time some contacts with Hydrography Office of the Polish Navy (HOPN) has been established. The concept of elaborating the formal method of valuation of availability of EGNOS service with defined level of accuracy has been discussed, and finally the written position of Chief of HOPN has been presented. The essence of this position means interest of Polish Hydrographers in the system supporting decision making officers in prediction the parameters of EGNOS open service in specified areas along the Polish Coastal Zone, especially in its central part. It is the result of using DGPS systems for hydrographic works in this area. Two DGPS stations are situated in two distant points close to the East and West borders and in fact in the central zone of the Polish Coast accurate positioning service is ambiguous.

\section{OBSERVATIONS}

Composition of formal method of valuation EGNOS service parameters could be realized only on the basis of elaboration of long term observations (measurements) in chosen points which are distributed in logical manner. According to foundations of the project measurement had to be executed in Gdynia (GDY), Olsztyn and Chełm (see the x on the Fig.1).

However the excellent cooperation with PANSA causes to change the plans and finally measurements have been performed in Gdynia in periodic campaigns and mainly as the permanent observations made in Kraków (KRK), Rzeszów (RZR) and Warsaw (WAW) by means PANSA monitor stations equipped with Septentrio PolaRx2e receivers. The advantage of these registrations is the uniformity of receivers. Gdynia registrations have been provided with different receivers, mainly dedicated sea-navigation: CSI Wireless 1, NOVATEL OEMV, Sperry Navistar, Crescent V-100 and Magellan FX420. 


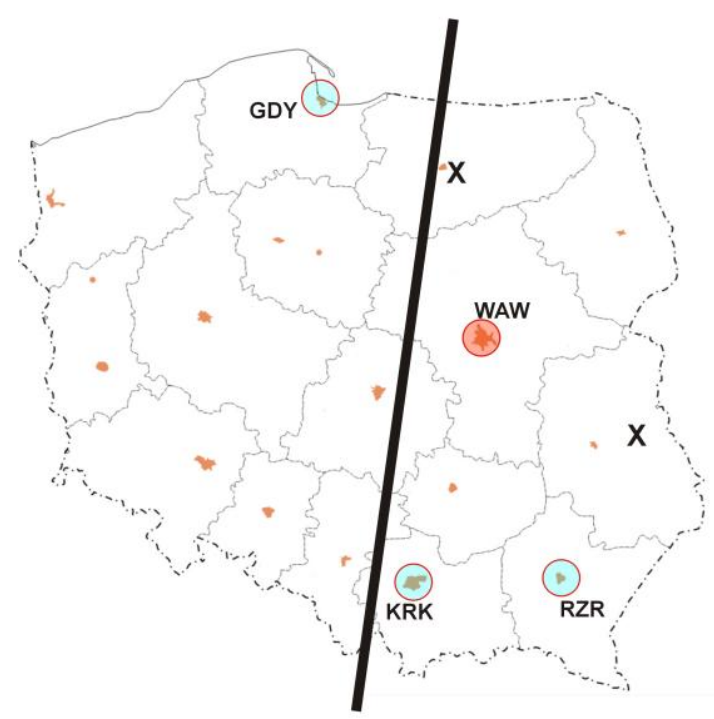

Fig. 1. Distribution of measuring points. Line on the map shows approximately the border of APV I service according the EGNOS Service Provision Yearly Report (April 2009- March 2010). ESSP-DIL51-R2010, rev. 01-02, 14.06.2010.

Registrations on PANSA stations have been completed every second during each whole month up to end of September 2010. However the period from 1 of October 2009 to 30 September 2010 is analyzed. This is because the first of October is declared as the beginning of full operational capabilities of EGNOS and in fact behavior of EGNOS before this date was noticeably different from the behavior after this date. Registration made with sea type of EGNOS receivers have been completed with the same frequency but performed in many campai gns lasting usually several weeks.

The main object of analyses was the accuracy and availability of EGNOS service in each point and for different receivers. Accuracy has been analyzed separately for each coordinate. Finally the temporarily and spatial correlations of coordinates and its accuracy has been investigated.

\section{SPATIAL CORRELATION OF MEASUREMENTS}

For aviation users of the system the vital question is an efficient notification system about the instantaneous quality of the service. This will be the attribute of Safety of Life service which has to inform users within 6 seconds about the lack of the integrity of the service. However, appears the question about relations among real parameters of the system in local conditions, and with notifications transmitted with SoL service which have a total character. A good manner of estimation of this problem is the comparison of accuracy and availability of the signal in three points of PANSA network equipped with identical receivers. Especially usable for it are results of investigations of availability of the signal in these points. Availability of the service was computed by means of PEGASUS software performed according requirements of EUROCONTROL. In this context availability means percentiles for the different approaches operations determined by dividing the number of samples that are available for an operation by the total number of valid samples and characterizes with the essential variability (see fig. 2.). As result of this analysis it appeared that, generally speaking there is a little correlation between availability in different points. 


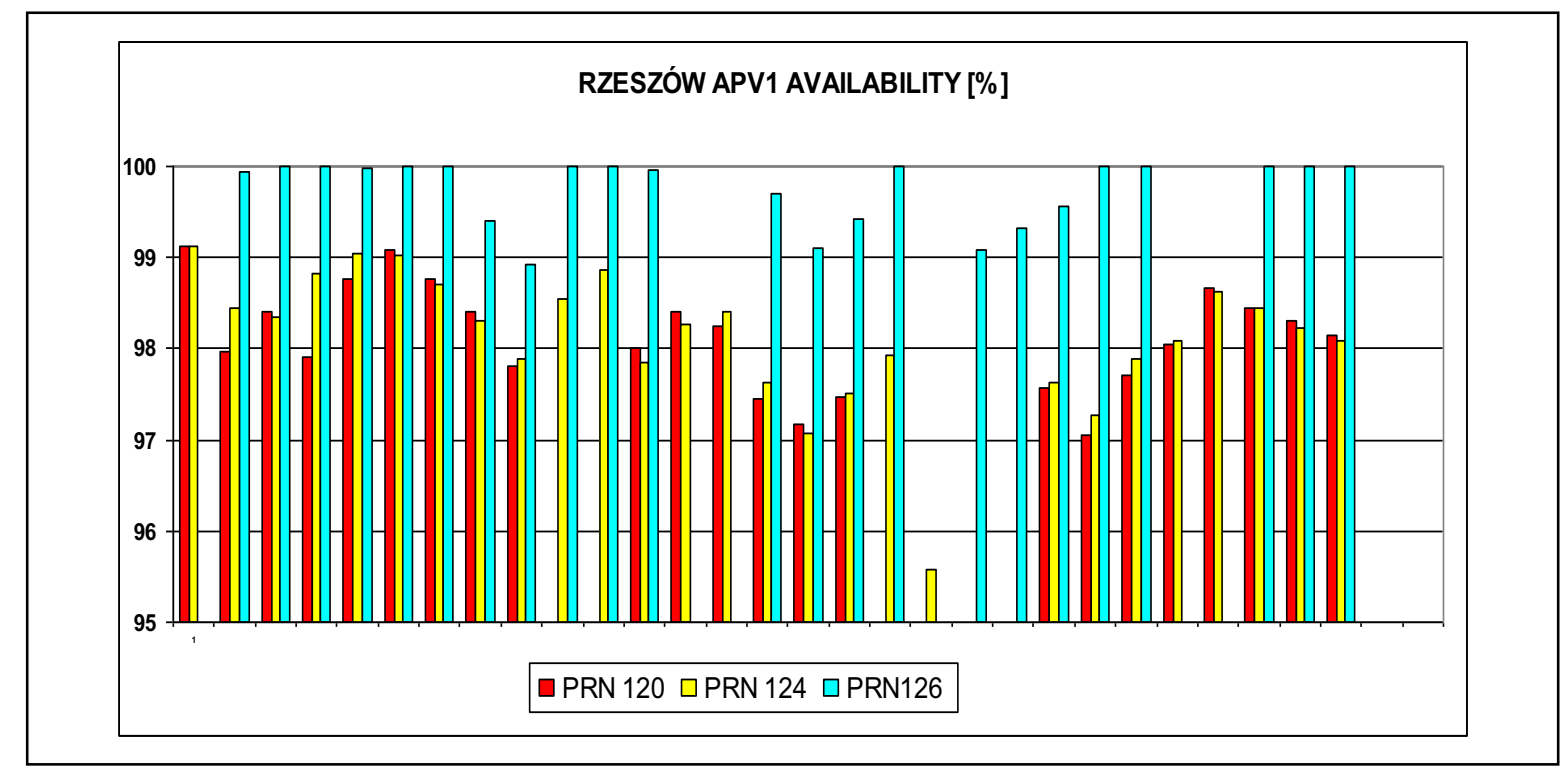

Fig. 2. Example of availability of APV I service in Rzeszow (May 2010).

In similar circumstances in one city the corrections has been received but in other one were not available. Even the availability of each satellite for the same receiver is different and this value has a random character. As an example coefficient of spatial correlation of availability of each satellite in different places in September 2010 is presented in Tab.1. According to numbers presented in the matrix availability of EGNOS service in the different points as well as for different satellites is different and correlation between them does not exist. What is more, correlation between the availability of the signal of the same satellite in different places is a random value. Only for ARTEMIS satellite it was almost 1 which shows important connections. With reference to other satellites it is impossible to predict the availability on the basis of information from other places or about the other satellite. This is argument for the opinion about the necessity of local monitoring of the system, aside the whole EGNOS net.

Tab. 1. Matrix of coefficient of correlation between the availability of different satellites in the PANSA net Sept 2010

\begin{tabular}{|c|c|c|c|c|c|c|c|c|c|}
\hline & RZR120 & RZR124 & RZR126 & KRK120 & KRK124 & KRK126 & WAW 120 & WAW 124 & WAW 126 \\
\hline RZR120 & 1,0 & 0,8 & $-0,1$ & 0,4 & 0,7 & $-0,1$ & 0,4 & 0,8 & $-0,1$ \\
\hline RZR124 & & 1,0 & $-0,1$ & 0,4 & 0,9 & $-0,1$ & 0,3 & 0,9 & $-0,1$ \\
\hline RZR126 & & & 1,0 & 0,0 & 0,1 & 0,4 & 0,0 & 0,0 & 0,2 \\
\hline KRK120 & & & & 1,0 & 0,5 & 0,0 & 0,9 & 0,5 & $-0,1$ \\
\hline KRK124 & & & & & 1,0 & $-0,1$ & 0,4 & 0,9 & $-0,1$ \\
\hline KRK126 & & & & & & 1,0 & 0,1 & $-0,1$ & 0,6 \\
\hline WAW120 & & & & & & & 1,0 & 0,5 & 0,0 \\
\hline WAW124 & & & & & & & & 1,0 & $-0,0$ \\
\hline WAW126 & & & & & & & & & 1,0 \\
\hline
\end{tabular}




\section{THE QUALITY OF THE RECEIVER AND ACCURACY OF COORDINATES}

For the project needs it was supposed that EGNOS receivers accuracy are not identically, and additional supposition has been made that the value of corrections received from the augmentation system constitute the main part in the budget of errors. From these reason tests of the accuracy of different receivers has been executed. The numbers in both tables present the influence of the type of the receiver on the accuracy of coordinates determined by means of EGNOS.

Tab. 2. Horizontal error (95\%) in Y2010

\begin{tabular}{|c|c|c|c|c|c|c|}
\hline & & WAW & KRK & RZR & $\overline{\text { GDY }}$ & WAW2 \\
\hline \multicolumn{2}{|l|}{$\mathrm{Jan}$} & 1,62 & & & 1,93 & \\
\hline \multicolumn{2}{|l|}{ Feb } & 1,60 & & & 1,86 & \\
\hline \multicolumn{2}{|l|}{ Mar } & 1,46 & & & & \\
\hline \multirow{3}{*}{ Apr } & 120 & 1,41 & 0,77 & 0,92 & \multirow{3}{*}{1,56} & \multirow{3}{*}{1,6} \\
\hline & 124 & 1,42 & 0,77 & 0,91 & & \\
\hline & 126 & 1,42 & 0,71 & 0,80 & & \\
\hline \multirow{3}{*}{ May } & 120 & 2,93 & 0,74 & 0,96 & \multirow{3}{*}{1,6} & \\
\hline & 124 & 1,55 & 0,75 & 0,96 & & \\
\hline & 126 & 1,58 & 0,67 & 0,82 & & \\
\hline \multirow{3}{*}{ Jun } & 120 & 1,43 & & 0,95 & \multirow{3}{*}{1,2} & \\
\hline & 124 & 1,46 & & 0,95 & & 1,22 \\
\hline & 126 & 1,41 & & 0,76 & & \\
\hline \multirow{3}{*}{ Jul } & 120 & 1,60 & 0,81 & 1,08 & \multirow{3}{*}{1,24} & \multirow{3}{*}{1,52} \\
\hline & 124 & 1,60 & 0,80 & 1,07 & & \\
\hline & 126 & 1,49 & 0,83 & 0,8 & & \\
\hline \multirow{3}{*}{ Aug } & 120 & 1,52 & 0,82 & 0,96 & 1,2 & \\
\hline & 124 & 1,53 & 0,81 & 0,98 & & \\
\hline & 126 & 1,49 & 0,74 & 0,85 & & \\
\hline
\end{tabular}

Tab. 3. Vertical error (95\%) (Y2010)

\begin{tabular}{|l|l|c|c|c|}
\hline \multicolumn{2}{|l|}{} & WAW & KRK & RZR \\
\hline Jan & 1,56 & & \\
\hline Feb & & 1,56 & & \\
\hline Mar & & 1,50 & & \\
\hline \multirow{3}{*}{ Apr } & 120 & 1,42 & 1,13 & 1,5 \\
\cline { 2 - 5 } & 124 & 1,44 & 1,14 & 1,5 \\
\hline & 126 & 1,42 & 1,08 & 1,3 \\
\hline \multirow{3}{*}{ May } & 120 & 1,43 & 1,11 & 1,46 \\
\cline { 2 - 5 } & 124 & 1,43 & 1,12 & 1,47 \\
\cline { 2 - 5 } & 126 & 1,33 & 1,05 & 1,31 \\
\hline \multirow{3}{*}{ Jun } & 120 & 1,37 & & 1,51 \\
\cline { 2 - 5 } & 124 & 1,37 & & 1,48 \\
\hline \multirow{3}{*}{ Jul } & 126 & 1,19 & & 1,27 \\
\hline & 120 & 1,48 & 1,20 & 1,57 \\
\cline { 2 - 5 } & 124 & 1,47 & 1,23 & 1,58 \\
\hline \multirow{3}{*}{ Aug } & 126 & 1,34 & 0,96 & 1,54 \\
\cline { 2 - 5 } & 124 & 1,50 & 1,32 & 1,49 \\
\cline { 2 - 5 } & 126 & 1,49 & 1,30 & 1,44 \\
\hline
\end{tabular}

Differences of accuracy between the same types of the receiver reach $100 \%$ this value and it is visible that the accuracy is more dependants of the location than the receiver. 
Moreover, in fact there are no differences of the accuracy among different types of receivers, which is presented in tables 2 and 3.

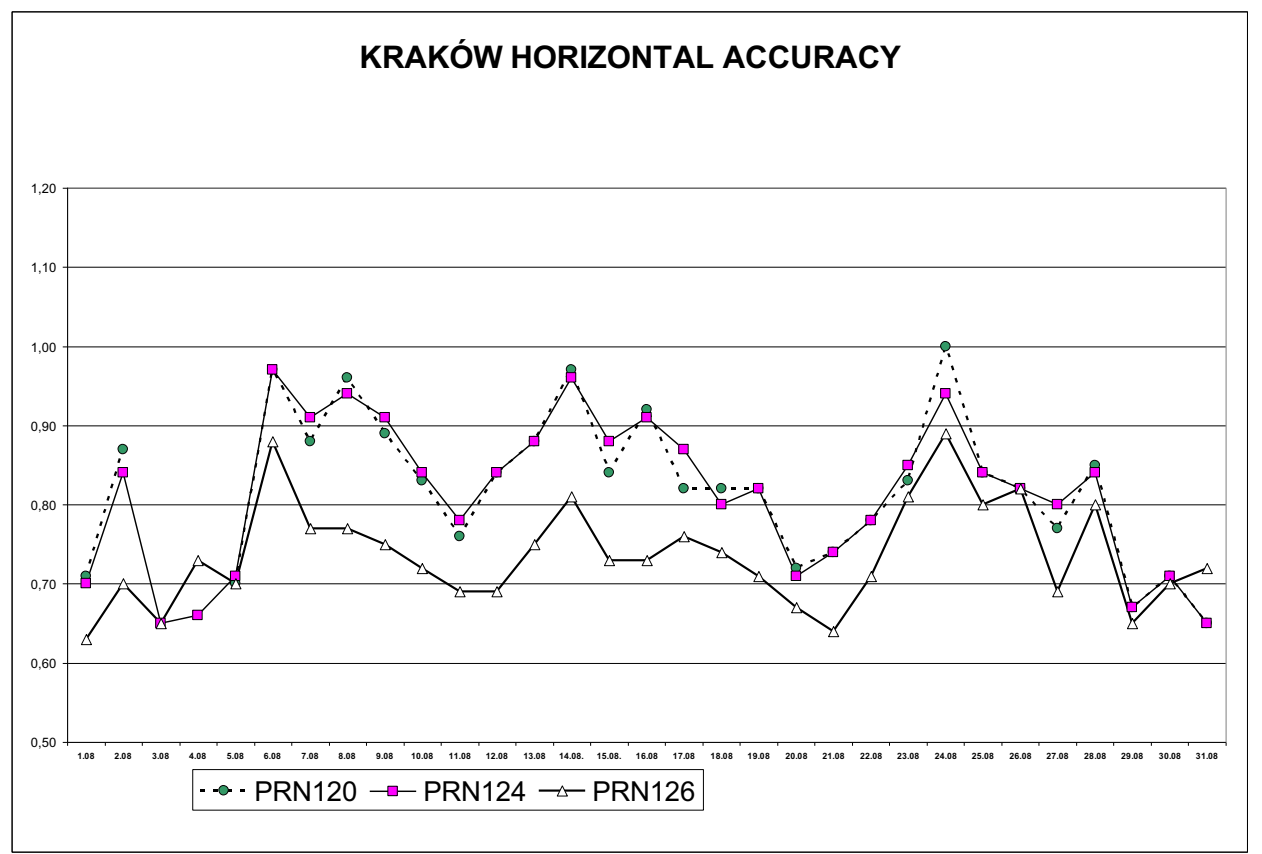

Fig. 3. Error of horizontal coordinates observed in August 2010 with reference to the SBAS satellites (in $[\mathrm{m}])$.

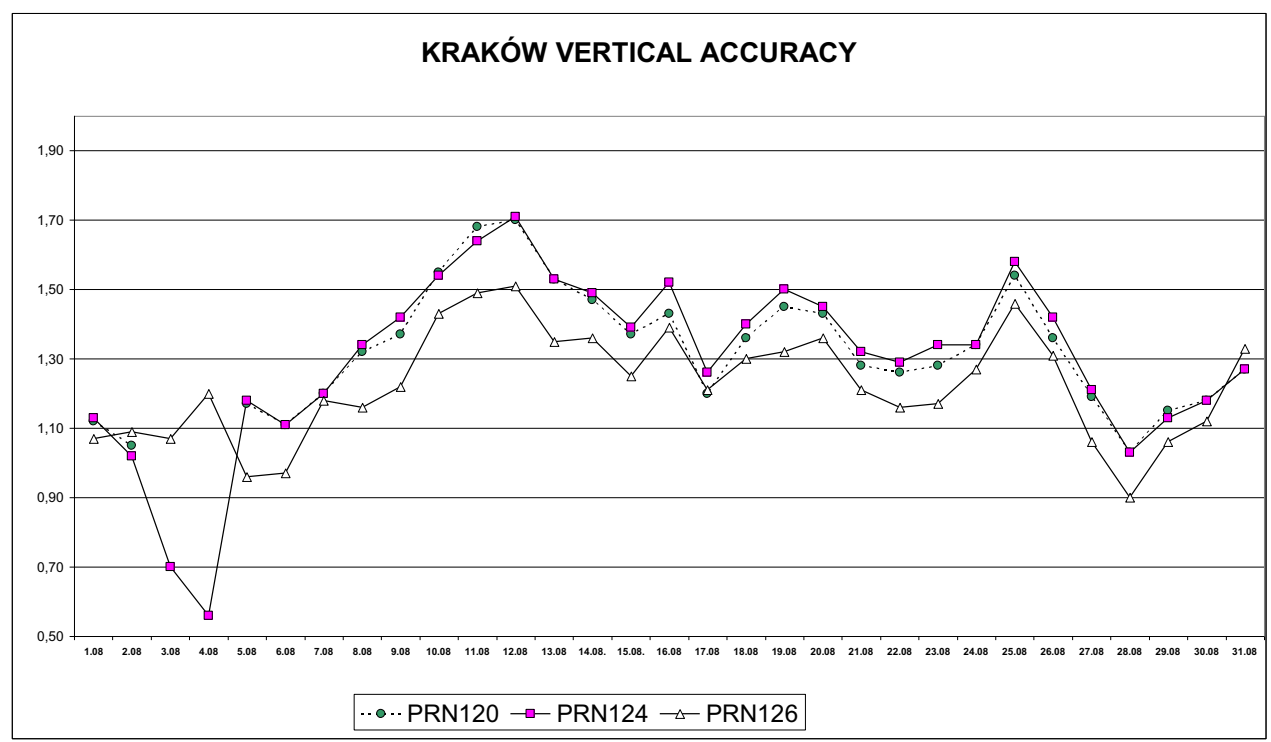

Fig. 4. Error of vertical coordinate observed in August 2010 with reference to the SBAS satellites (in [m]).

These differences are similar as for PANSA net receivers, and it should be interpreted as an influence of the location, and not the type of the receiver. Summarize the problem we can say, that EGNOS horizontal accuracy is not worst than $1.5 \mathrm{~m}(95 \%)$ and standard deviation of vertical coordinate is about $1,4 \mathrm{~m}(95 \%)$ and in fact it not dependent of the receiver. However the accuracy has correlation with the location in relation to the coverage zone of the system. There are noticeable relations between accuracy and the number of SBAS satellite. As an example, accuracy in Kraków (KRK) in August 2010 is presented in the figure 3 and 4 . 
According to the theory the accuracy is correlated with the distance to the RIMS station or to the border of the EGNOS activity zone. However according to ESSP information every PANSA station are situated out of EGNOS APV I service coverage, even WAW, when RIMS station is situated. Presented results shows that the distribution of the station has no direct influence on the quality of measurements, because accuracy obtained in Rzeszów and in Krakow are very similar, instead accuracy obtained in Warsaw are clearly worse, in spite that RIMS station is situated there.

\section{THE REPEAT ABILITY OF COORDINATES}

The orbit of the GPS satellite is a twelve hours orbit, so similar values of geometrical coefficients DOP will periodically repeat. EGNOS so as all augmentation systems is a tool to correcting the errors of the signal, so assures the minimize $\sigma$. However the geometrical coefficient does not change. The influence of this factor is perceptible then, when will be analyzed variability of the accuracy in shorter sections than of twenty-four hours. Then are perceptible changes of the average position and its errors.

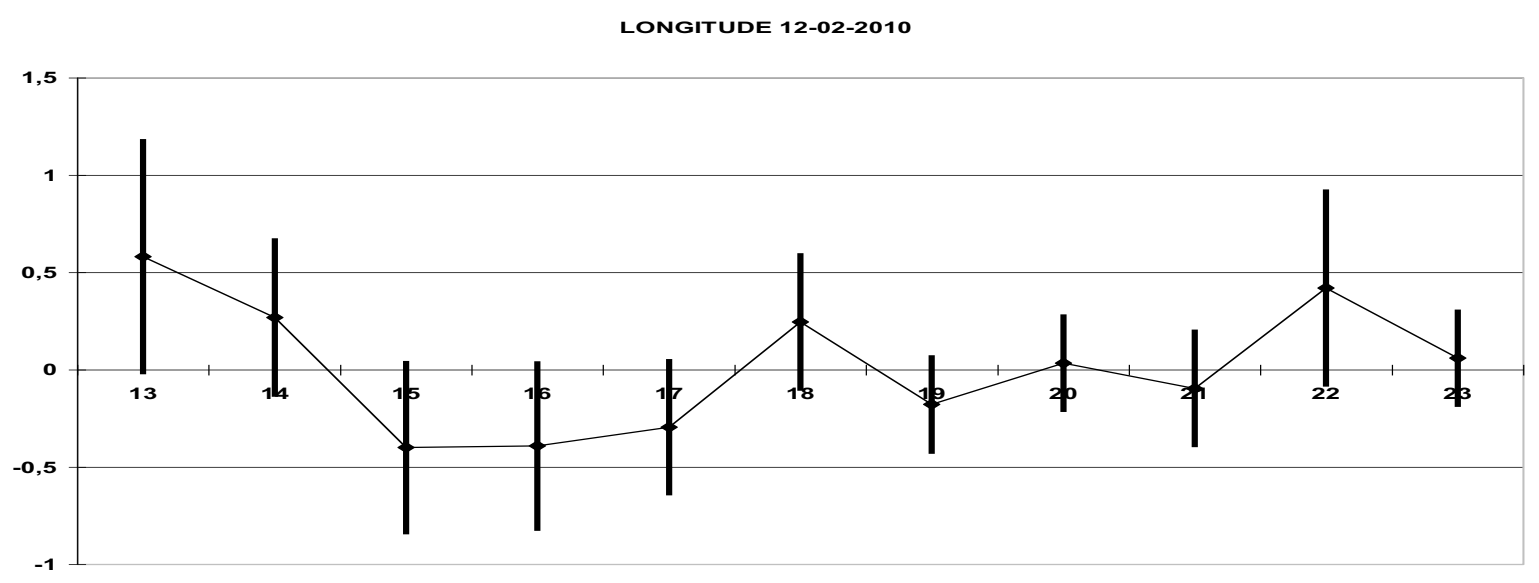

LONGITUDE 13-02-2010

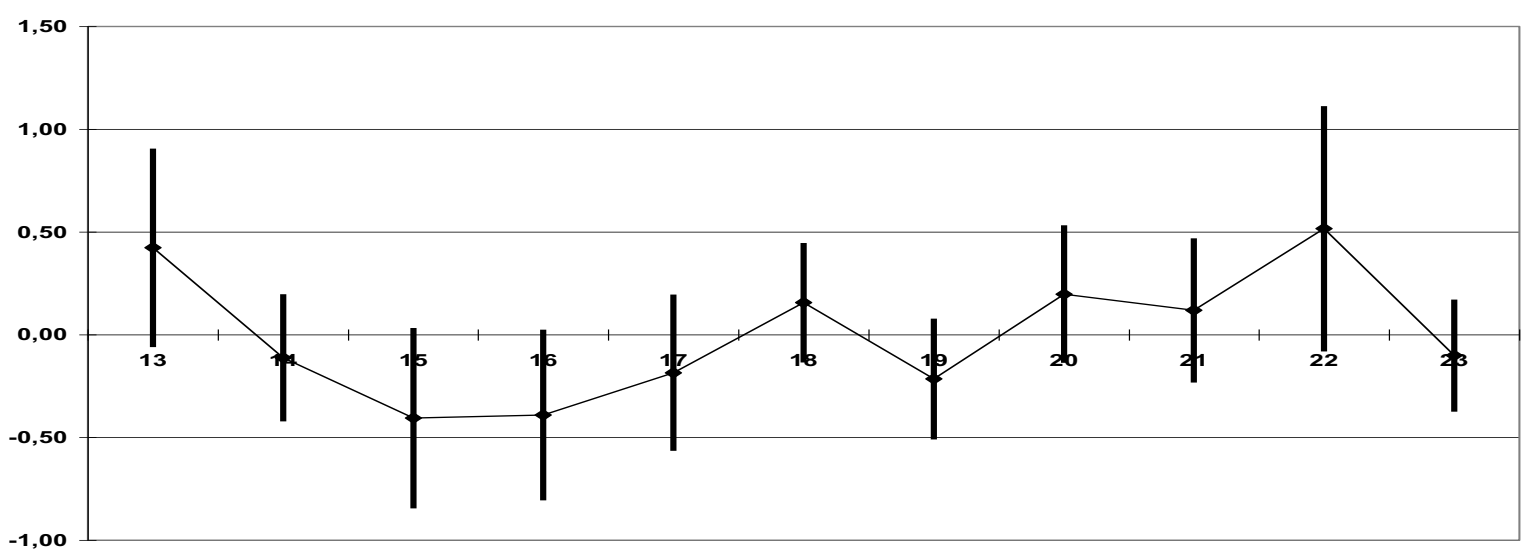

Fig. 5. Changes of the longitude in hour's sections and standard deviations in Gdynia in adjoining days (in $[\mathrm{m}]$ ).

On figure 5 changes of the longitude in Gdynia are presented in the period between 12 and 23o'clock in days 12 and 13 of February measured by means of NAVATEL receiver. Clearly it is visible that very similar is the shift of the average position for the temporary sections, and also the standard deviation of coordinates in these sections. In authors' opinion this repeatability is a premise to forecasting of the quality of coordinates. 


\section{CONCLUSIONS}

The main object of referred analyses was the accuracy and availability of EGNOS service in four points on east part of Poland as well as for different receivers. Accuracy has been analyzed separately for each coordinate. Finally the temporarily and spatial correlations of coordinates, its availability and accuracy has been investigated.

The findings prove that present accuracy of EGNOS service is about 1,5m (95\%), but availability of the service is still not satisfying, and even controversial. The accuracy of present EGNOS service meets the parameters of APV I and even APV II requirements, as well as any maritime and hydrography needs. However introducing this service into the practice demands better availability, because the gaps in receiving the proper information from the system appear too often and are too long at the moment. Additionally it was noticed very random character of availability and no correlation of this parameter in the different point of observations. The same awareness can be referred to the correlation among the accessibility of corrections transmitted via different satellites. In spite the correct EGNOS work the accuracy of the coordinates is many times not predictable in the local conditions. So in authors' opinion Local Airport Monitoring should be deployed if EGNOS would have to serve to the local airport service.

\section{REFERENCES}

EGNOS Service Definition Document. (2009) Ref.: EGN-SSD OS v 1.0. Open Service. European Commission. Directorate-Generale for Energy and Transport.

EGNOS - A Cornerstone of Galileo. (2007). SP-1303. ESA.

Federal Radionavigation Plan 2008. National Technical Information Service, Springfield. DOT-VNTSC-RITA-08-02/DoD-4650.5.

Global Positioning System Standard Positioning Service, Performance Standard. Assistant Secretary of Defense, Washington DC 2001.

http://www.essp-sas.eu/news, 22.03.2010.

Miesikowski M., Nowak A., Oszczak B., Specht C. EGNOS - accuracy performance in Poland. Annual of Navigation No. 11, Gdynia 2006.

User Guide for EGNOS Application Developers. ED.1.1. CNES, ESA. 2009.

Received: 2011-12-06,

Reviewed: 2012-01-18, by S. Oszczak,

Accepted: 2012-01-19. 